\title{
Redefining ecological trajectories: Paradigms and beyond
}

\author{
Dipleena Saikia \\ Jawaharlal Nehru University
}

\begin{abstract}
This paper is an attempt to analyse the onset of the issue of ecological paradigm and how it is context specific. The paradox of the western dissent of ideas and the newer perspective which sheds light upon the spaces which were never discussed before; it enables a fresh perspective through the methodological approach of relational sociology. On the onset of Paradigms as ways of categorising stories into groups, this paper is an attempt at unfolding the limitations to the concept of an archtype through the eyes of a social phenomenon. It allows the paradox of ideas which holds on to the archtype nature of a concept to allow itself to negotiate through the process of parallel developments, infact open itself to a newer idea on its own.
\end{abstract}

Keywords: ecological paradigm, relational approach.

\section{Introduction}

The term 'Paradigm' is derieved from the Greek word (paradeigma) which means 'Pattern' or 'example' from the word (paradeiknunai) meaning 'demonstrate' of explaining social facts not only with social facts. Instead, they include physical and biological facts as independent variables influencing social structure. 'Social structure' refers to the idea that the society is grouped into structures with different functions, meanings or purposes. Family, religion, Law, Economy ans class are all social structures.

Environment and Man relationship has been contested over the years for the cause of usage of resources and Man claiming to be an omnipotent user of the same. The very definition of resources has been used deliberately to provide the mankind with the functionary purposes of the Environment. As difficult as it sounds, the idea of change in the constant process of its 


\title{
SOCIAL SCIENCE, HUMANITIES \& EDUCATION
}

\author{
21 - 23 JUNE 2019 \\ VIENNA, AUSTRIA
}

usage is not only difficult but paradoxical in nature. The simpler the understanding of it sounds, the harder it is to act upon it. Historically, the study of enviromental sociology was focussed on modern industrialised societies and the initial decade of introduction of schools of thought about how humans relate to the environment was only during the 1970s. Riley Dunlap, contrasts the dominant western worldview with the human exemtionalist and the new ecological paradigm. He links these paradigms to undefying sociological theories about human motivation and decision making. The interdisciplinary approach sets towards the diversification of the complimented frameworks. Socio environmental interaction and Man's relation with the environment is a vast connection of clues to understand how the relationship works along with the framework of social, economic, political counterparts of it. Intellectual developments are mostly paralleled by the organisational developments. American Sociological Association was one of the first organisations to include a part of the onset of man and environment relationship in 1976. The dominant paradigms have initiated the thought process and ideas which resonated all over the world during the decades that followed. The exemptionalist view was one such paradigm which initiated the thought process of a Human exemptionalist Paradigm. It denotes to how humans are superior to the environment. Led by 'Catton and Dunlap'; the two pioneers of the 'HEP' and 'NEP' paradigm led on to analyse the NEP paradigm as 'New Ecological Paradigm'. The view suggests that Man is dependent on the envionment and the human societies and both are interrelated. In the Paradigm inititative, this was led by American Sociologists who wanted to work upon the relationship between man and the environment.

After the onset of 'HEP' and 'NEP', many associations all over the world tended to this discourse and it led towards an upsurge in external relations. Foreign affairs, economy, political affairs, arts and religion and so on. What we falied to understand with the idea of it is, the emergence of existing Paradigms with their wolrdview on Environment and Man relations and issues. Weberian and Marxian perspective along with Durkheim dominated the sphere of it and never furthened their thoughts over it because of the untimely need of the hour and the want in social and structural explanations of thier theories and ideas. It never resonated a glocal approach until now. Ecological variables were not included in Social analysis. 


\title{
SOCIAL SCIENCE, HUMANITIES \& EDUCATION
}

\author{
21 - 23 JUNE 2019 \\ VIENNA, AUSTRIA
}

In India, scholarships of Ramachandra Guha and Ramakamal Mukherjee were among the firsts to establish the field in the forefront. In 1920s Radhakamal Mukherjee proposed the region as a concept that would allow the systhesis of ecology and sociology. Any human group, wrote Mukherjee, must be considered in relation 'not merely to temperature, humidity, sunshine, altitude etc, but also their indirect effects, the interwoven chain of biotic communities to which it is inextricably linked, the plants that it cultivates, the animals it breeds and even the insects which are indigenous to the region. (Baviskar, 1997)

Patrick Geddes was one such urban planner who brought sensitivity to the topic of ecology while planning the then towns such as Lucknow, Patiala, Dacca. Ramachandra Guha's essay on 'Prehistory of Indian Envidronmentalism' (Guha, 1992) highlights the works on Geddes , Kumarappa and Mukherjee. Other scholarships on relationship of man and environment through the Dalit perspective, have also evolved over the decades. The hitherto neglected area of the relation between human beings and nature amd the deleterious effect of human action upon the latter, especially in the last century and a half, has emerged as a major issue. Another issue in contemporary theory is the growth of environmental politics/movements which offer a challenge to the modern industrialist/capitalist mode of production and consumption which are environmentally destructive. What follows is an elaboration on some of these issues. (Munshi, 2000)

American and European trajectories are different from the rest of the worldview in the sense that it correlates to phenomenon which are often times only relatable to the specific conditions in the places where it evolved or were created. The ideas tend to revolve around the spaces it has inhabited its shape from and is very different from the spaces which vary longitudinally as well as latitudinally. It not only revolves around the ideas of global agendas persisting to change in a global order, it also prohibits the narrower and little spaces to be explored and understood. If we move forward with the associated ideas of trajectories which are only available in scholarships found purely on the basis of where it started first in the world, it is very difficult to move forward with the smaller spaces which move forward parallely in its own distinguished spaces. 


\section{SOCIAL SCIENCE, HUMANITIES \& EDUCATION}

\section{1 - 23 JUNE 2019 \\ VIENNA, AUSTRIA}

The Indian trajectory has seen movements and social changes as the order to initiating dialogues and they cohabit with the changes. Gadgil and Vartak, Guha being some of the pioneers of the scholarships available are one of the reasons of which we are ablw to understand the difference of it. The idea that it is context specific denotes to the fact that relational analysis is one of the important aspects of undermining this change and variant. The variant may be in the form of social inyteractions, or the use of resources and its order or basis, the livelihood and its interdependence on the environment and so on. Point is, the methodological consequence of it has initiated the amount of difference that can be seen in the works of many.

\section{An ecological perspective}

When we talk about newer perspectives we know it is a clear demarcation of where weve come from and what are the future aspects of it. When we talk abou the emergence of a new found paradigm in the existing sources, we tend to overlook the fact that it might be able to produce a new idea of its own. The new himalayan study perspective has led towards the occurence of discourses over trajectories, spaces and beyond. Issues on environment and health, differences in ethnic commons and environment as such are the basis of the paradigm shift that has raised questions to the existing idea by giving ahead a fresh perspective to start with. Relational analysis is therefore the method to understand how the context specific issues are generated within. Objects under the investigation are seen in context as a part of a whole. Their meaningfulness is determined not by characteristic properties, attributes or essences of the thing itself, but rather with reference to the field of objects, practices or activities within which they are embedded.

The paradigm shift from an Orientalist approach to the indigenous rational approach reciprocates with the idea of the changing trend in the approach towards the development of ecological theory. This method understands the importance relationship among the humans and the environment. The rationality that the indigenous mankind may posses will be very different from the global perspective and even the agendas that our government organisations may come across to objectify and substantially use it to make changes in the manner that they think must help. This not only defies the perspective which have evolved over the ages but questions the foundation of it with the help of this method. 


\section{SOCIAL SCIENCE, HUMANITIES \& EDUCATION}

\section{1 - 23 JUNE 2019 \\ VIENNA, AUSTRIA}

Relational analysis in knowledge production, helps people understand the ideas and its importance through the connections of a human with the environment they live in, and the relational aspect of it. The more the context is clear, the more the ideas become vivid and clear. This relationship defines the whole structure of how indigenous knowledge production has helped mankind grow and evolve over the years and is shaped by the cultural and social phenomenon that occur in their day to day lives. The use of beads in traditional customs in Northeastern state of Arunachal goes way back to their account of travel diaries associated with the daily lives of the people and their relation with the environment. The historical linkage is understood just with the help of their oral traditions used in their day to day practices. (Blackburn, 2003).

DUNCAN's POET model includes population, Organization, Environment and Technology as its framework for the variables that he used to interrelate society and the environment. New Human ecology which later was termed as HEP (Human Exemptionalist Paradigm) was influenced largely by the works of Malthus and the population overshoot theory.

It has been observed that 'contemporary forms of environmental degradation present one of the most, if not the most, complex and catastrophic dilemmas of modernity' (Goldblatt, 1996)The recent upsurge of environmental concerns be it through movements, social activism, political agendas so on and so forth can be seen increasing the horizon of the environmental catastrophe's realisation. It is what we call the environmental 'havoc' period. The movements that have occured due to the rise in environmental concerns gives a clear picture of the use of resources as the problem in itself because its finite. What is infinite is the amount of expected outcome of it, and its usage which grows everyday and never ceases to lapse. Social actions in the process of natural resource usage can be seen to be poorly embedded in mainstream sociology as pointed out by Murphy (Murphy, 1997). Anthony Giddens and Jurgen Habermas were some of the thinkers who indulged into the affairs of the environmental problems in sociology as constructivist in human actions. They addressed these issues on the forefront.

In Giddens view, the debate about whether capitalism industrialism has been the prime mover in shaping the modern world until relatively recently, ignored the destructive effects but modern production systems may have upon the environment (Giddens, 1987). Giddens saw problems 


\section{SOCIAL SCIENCE, HUMANITIES \& EDUCATION}

21 - 23 JUNE 2019

VIENNA, AUSTRIA

in the capitalist and industrialist approaches to destruct the societies and the environment as a whole specially the developing societies and nations. It is when the scholarships led towards an advancement among the paradigms from specific worldview to the space specific view which open newer horizons and perspectives. It led towards breaking free from the dominant view which went parallely with the lesser effects of environmental problems in sociology.

\section{Environmental concerns in India}

Patrick Geddes being the pioneers of Indian environmental problems in India, went about to create a new found challenge in the Indian subcontinent regarding urban planning and usage of spaces altogether. He argued that the spaces should be built in accordance to the need and the rationality of the region and with the specificity of the region at best. It was necessary to understand the problems and to fimd the solutions to it and not altering the relationship altogether. Ramachandra Guha made efforts to understand the village ecosystem and to understand the problems of the poor, find apt solutions towards urban planning and development of the same. In the developing nations, especially a nation as India needs careful planning be it the spaces or the relationship we tens to acknowledge among the people and environment simultaneously. It enables us to see towards a newer perspective of need basis according to the space required and not the conundrum of development of a region altogether. These scholarships enabled the idea of space to be taken in account of the planning and development during the initial period when environment as a paradigm was still a newborn among the sub altern studies.

Peasant insurgency, post colonial industrialist policies led towards an upsurge in the questioning of mankind's relationship with the environment. When compared with the American association or the European Association, it was much much later in terms of providing a basic structure to the discourse in the Indian subcontinent. It is very clear of the fact that we tend to learn the ideas through the Orientalist approach and then tend to overlook the perspective of its own, to say so. It is not specific to core and periphery per se, but the idea of 'space' here is in terms of the ecological trajectory which varies from region to region. When we talk about communities we cannot generalise and look at the environmental problem as a phenomenon which only relates to the relationship between mankind and environment as a 


\section{SOCIAL SCIENCE, HUMANITIES \& EDUCATION}

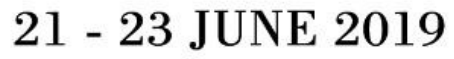

VIENNA, AUSTRIA

'resource'. It is something more than that. The idea of this ecological trajectory relates to the difference in an individual relationship wuth the environment as well as the community's relationship with the environment. I

Many scholars used the colonial period as the important phase of human history to understand the environmental degradation and its core point being the colonial records to use as their methodological explanation to it. Several studies have focussed on the colonial upsurge and environmental degradation of the resources through the areas of administration, and colonial intervention. This use of natural resources had led towards undermining the capacity of resources to deplete over time. It also has a shared history of human relationship among themselves and use of human as a resource along with the environment. This hegemony had created an enormous amount of upsurge among the then scholarships which led towards an awakening of the environmental degradation.

Discussion among the social upsurge and the activists regarding Chipko movement, and Narmada Bachao Andolan to name a few have been the pioneers of contemporary scholarships to be written and acknowledged. It has been difficult yo understand spaces though in terms of the regions which were specific to these orders of destruction.

Northeast India termed as the 'boiling pot' of carious cultures comprises of the heterogeniety of the people. First teachings of sociology established in the region was in the late 1960s, specifically in the year 1967 when Dibrugarh University was established. K.B Nayar, and S.M Dubey were one of the pioneers of the scholars in in Northeastern region of India. Often confused with the ethnographic studies or anthropolgy, due to the dominance of cultural framework in the habitat, this region saw a very gradual process of framework across the region.

When we analyse through relational approach the idea of the spaces seem to be a distinct one. Relational analysis helps understand the compact understandings of cultural phenomenon across regions and untangle them using the space and time decorum longitudinally and latitudinally. This allows to understand the relational aspect of human and the environment at a clear point of view. S. M Dubey during his course of period tried to understand the sociology 


\section{SOCIAL SCIENCE, HUMANITIES \& EDUCATION}

\section{1 - 23 JUNE 2019

of tribes with emphasis on the study of social structure, change and development among the region along with the process of modernization.

The formation North East India Sociological Association in the year 1973 under the leadership of S.M Dubey led towards an achievement of the starting point of scholarships in the region. (Dubey, 1981)

When talked about folk ecology as an example to understand this relationship between man and the environment, the behavioural patterns and the cultural phenomenon stands entirely space specific be it the relationship among human to human or the relationship between human and the environment. The idea that it has led towards understanding this specific issue leads towards newer perspective of relational attitudes towards the same. This relational attitude allows an approach to understand and decipher the patterns or variables required to move forward with the context specific issue of environmental degradation.

\section{Ecological Paradigm}

The believed norm in environmental psychology among the mankind is the participation in a setting to relate to each other and interacts with each other gets affected by various external forces be it the nevironment or the psychological pattern among the individuals. There are some deterministic views of the environment behaviour that environments have the direct effect on people or indirect effect. These patterns affect the interpersonal relationships among the people living in a specific region.It tends to be more culturally specific or situationally specific. When we talk about theory we tend to give an explanation of a phenomenon whether whereas when we talk about the paradigm we generally tend to have a general perspective upon a phenomenon given the assumptions we make after observation. Environmental Determinism determines the proximity of neighbours which promotes interaction among the individuals.

When determining the factors of relationship among the individual and the environment we tend to contextualise the amount of determinants required for an individual to interact with the environment and the fellow individuals. Ecological paradigm therefore leads towards attaining an onset goal towards achieving a similar agenda regarding ecological resources to be used for individual or community purposes. It later on generalised into an extent which led towards 


\section{SOCIAL SCIENCE, HUMANITIES \& EDUCATION}

\section{1 - 23 JUNE 2019 \\ VIENNA, AUSTRIA}

distancing our close relationship with the environment and the activities led towards more patterning of functional distance between the people and the environment.

The different patterns in ecological paradigms may include: 'Sociopetal' and 'Sociofugal' aspects in it. Sociopetal aspects are designed in ways that bring people together i. E in informal spaces. Whereas Sociofugal aspect determines the minimization of interpersonal contact i e im formal spaces. We tend to use this behavioural pattern to determine the physical act towards ecology and its use over and over again which leads to exhaustion of resources. Both Sociopetal nad Sociofugal aspects are important in understanding the authenticity of the patterns associated with approaches towards human environment relationship.

\section{Relational Approach}

When we talk about dependency of human beings over the environement, we tend to overlook the facts on how the both are interdependent yet Humankind stays indifferent of its actions and the consequences. The whole trajectory of spaces is therefore linked towards the idea of relational approach to understand the interdependence of human and environement and on what basis. The idea behind its orientation is specific to the space and its origin through the perspective which cannot be substatiated without the scholarships and the already drawn paradigms and their ideals.

To deal with this problem, the ideas are negotiated throughout the issue of context specific human-environment role in the society. We necessarily undermine the relation of human and environment as merely the patterns anad behaviours that the society as a whole posseses.But what we donot understand is the intricacies that lie within. For example, the folklores, the traditional methods used and the orality expanded beyond horizons to lead towards acculturation, new found ideas of globalisation and the specificity of the parallel world that lives in urban and non urban spaces. When we decipher these movements as a part of the whole process, we tend to overlook the fact that its relation in its entirety cannot be generalised. Also, the fact that the entireity of this whole human and environment relationship is generalised on 


\section{SOCIAL SCIENCE, HUMANITIES \& EDUCATION}

21 - 23 JUNE 2019

VIENNA, AUSTRIA

the basis of paradigms associated within the boundaries of Orientalist and paternalist approaches throughout time.

\section{Nature and the Society: Various perspectives}

The various advances in the modern day phenomenon be it in the developments in social theory, biology, ethnobiology, sociology of science and its relationship with the other domains also prove to be an important voice towards the need for a doscourse and a shift in paradigm. The European Association of Social Anthropologists (EASA) was inaugurated in January 1989, in response to a widely felt need for a proffesional association which would represent social anthropologists in Europe and foster co-operation and interchange in teaching and research. As Europe transforms itself in the nineties. The EASA is dedicated to the renewal of the distinctive European in social anthropology (Palsson, 1996)

Societal environmental dialectic involved political jutting. It was put forward by Allan Schnailberg in the year 1975 who proposed the perspective of the conflict over state and the resources. The stages included,

Firstly the state will acquire enormous amount of economic expansion with the help of available resources at its expense.

Secondly, government will try to control the most important environmental problems to find a solution towards disasters to be prevented. This allows the Government to initiate concious act of appearing as environment concious than they actually are.

Thirdly, the ecological synthesis generates a dire hypothesis that the actions are to be taken to counter attack dire consequences by the Government. This gave rose to potential outcomes such as: Most powerful status quo maintained political forces will foster the dominance. Other results may be redistribution of resources for the same.

What is important to understand here is the relationship between the human and the enviroment is solely and most importantly largely based upon the ideas of omnipotency of Humankind and 


\section{SOCIAL SCIENCE, HUMANITIES \& EDUCATION}

21 - 23 JUNE 2019

VIENNA, AUSTRIA

its need for use of resources. What other factors the relational analysis amy posses is that societies are acting as a force interplaying their own courses among the interrelationships of human to human approach and environment plays a role in it. But, it is to be argued that it is the other way around. The environment plays its role as a distinguished force and the interrelationships among the humans are a part of it. As Sorokin says, "Any analysis of a social phenomenon which does not take into consideration geographical factors is incomplete".

The binary between the contestation of usage of resources and the saving of the same seems to be problematic. Given the idea of context specific issue, environement sociology takes into account the social relations which enable the human to inculcate patterns and behaviours. It can further be used to analyse the relationship with the environment and the core ideas related to it can be redifined with the spaces.

These spaces therefore cannot be generalised on the fact that the it is the same pattern and behaviour everywhere. Infact, it is so not similar in the sense that every space acquires its own pattern and behaviour and the relation with the external forces within and out proves to be different . Be it cross culture, acculturation, religion adn its significance, the economy and the influx of never ending technological advancements and so on.

\section{Spaces: Continued}

Whether the climate, or the pattern of wind system : cold currents, hot currents or the cultural diversification among the communities across the globe, the phenomenon of Human and Environment relationship cannot be generalised and juxtaposed over the centuries all over hte places around the globe. This is true in terms of longitudinal or latitudinal aspect in the sense that, the above comparison among the global scholarships and the regional ones have much of a diverse thought processes to begin with. To generalise the potent understanding of it will generalise the whole concept of man and environment realtionship and the human ecological behaviour associated with it. Manhy a times, we fail to understand it without analysing the relational aspects of it. We contribute to the associated domains through the approaches that are acknowledged as paradigms already. We generally overlook the fact that it needs 


\section{SOCIAL SCIENCE, HUMANITIES \& EDUCATION}

21 - 23 JUNE 2019

VIENNA, AUSTRIA

scrutinization in the aspect of space and its forms of hybridity, the patterns associated with it are more into the patterns that we go through in relation with the human behaviour and not the direct relation with the environment as such. Communities which are studies longitudinally are tended to have varied patterns which are known to influence the behaviour of individuals towards the environment.

This approach was described by one of the articles by Richard York published in 2003 which tried to explain variation and national level footprints. It used latitude as a proxy for climate as a predictor variable. Surprisingly they found latitude had a significant effect. The question was not raised regarding the onset of environmental determinism, but some of the scholarship has raised important questions regarding the warnings of 'climate determinism'. We tend to fail to determine the causable aspects of longitudinal constraints such as climate and topography as the imapct to the occurence and rather see it through the latitudinal spaces of race, and class and not understanding the environmental impacts as the sole basis of it.

The larger the phenomenon the more the forces tend to shape our thoughts and processes. The binary between the adherence of the environment among the social phenomenon and the posterity of environment as a part of human life is to be questioned. This would not only allow to understand newer spaces and the phenomenon will be understood very clearly and infact with more clarity. These paradigms have given a push towards the new found ideas of environmental criticism to the extent of marginalisation, thus the paradox. But the constant upsurge in the paradigms and it shifting from academia to movements goes beyond the ordinary assumption of future environmental aspects and ecological trajectories.

\section{Bibliography}

Baviskar, A. (1997). Ecology and development in India: a field and its future.

Blackburn, S. (2003). Memories of Migration: Notes on legends and beads in Arunachal Pradesh.

Dubey, S. M. (1981). Sociology in Northeast India: a souveneir of NEISA.

Giddens, A. (1987). Social theory and modern sociology.

Goldblatt, D. (1996). Social theory and the environment.

Guha, R. (1992). Prehistory of Indian Environmentalism. 
Munshi, I. (2000). Environement in sociological theory. Sociological bulletin .

Murphy, E. (1997). Constructivism: from philosophy to practice.

Palsson, P. D. (1996). Nature and Society. 